\title{
Alterations in Fetal Kidney Development and Elevations in Arterial Blood Pressure in Young Adult Sheep after Clinical Doses of Antenatal Glucocorticoids
}

\author{
JORGE P. FIGUEROA, JAMES C. ROSE, G. ANGELA MASSMANN, JIE ZHANG, AND \\ GONZALO ACUÑA \\ Center for Research in Obstetrics and Gynecology, Department of Obstetrics and Gynecology [J.P.F., \\ J.C.R.,G.A.M., J.Z.], Wake Forest University School of Medicine, Winston-Salem, NC 27157; and \\ Montevideo, Uruguay, Cp 11600
}

\begin{abstract}
ABSTR
Epidemiologic studies have yielded controversial information
regarding an association between antenatal steroid administration
and elevations in arterial blood pressure (BP). The aim of the
study was to determine whether antenatal administration of a
clinically relevant dose of steroids at a time when fetal nephro-
genesis is at its highest results in abnormal kidney development
and adult hypertension. Pregnant sheep were treated with either
vehicle or betamethasone. Maternal injections were given 24 h
apart at 80 d of gestational age (dGA; 0.55 of gestation). Animals
were studied either as fetuses or as immature adults. Fetuses were
delivered by cesarean section at 135 dGA. Adults were studied at
6 mo of age. Betamethasone administration did not induce
premature labor or intrauterine growth restriction. In the beta-
methasone-exposed group, we found at 135 dGA a $25.5 \%$ de-
crease in the number of glomeruli with no differences in fetal
kidney weight. In adults, mean, systolic, and diastolic arterial
\end{abstract}
BPs were significantly higher, whereas there were no significant differences in heart rate over the same study period. The major finding of this study is that a single course of antenatal steroids alters renal development and is associated with elevations in arterial BP in lambs at 6 mo of age. We conclude that antenatal glucocorticoid administration under the National Institutes of Health consensus guidelines may alter human fetal renal development. (Pediatr Res 58: 510-515, 2005)

Abbreviat angiotensin receptor
BP, blood pressure
dGA, days of gestational age
PAH, para aminohippuric acid
RAS, renin-angiotensin system

The pioneering work of Liggins and Howie (1) resulted in antenatal steroid treatment's becoming standard of care for enhancing fetal lung maturation in pregnancies that are threatened by premature labor between 24 and 34 wk of gestation. Following the National Institutes of Health consensus conference recommendation (2), the use of corticosteroid therapy in the United States has increased from $<15 \%$ of individuals who threatened to deliver prematurely in 1990 to $>75 \%$ now (3). However, the growing use of glucocorticoids in the perinatal period has become an issue of extreme concern because of the potential for untoward effects found only with long-term outcome studies $(3,4)$. A recent epidemiologic study shows an

Received November 11, 2004; accepted February 3, 2005.

Correspondence: Jorge P. Figueroa, M.D., Ph.D., Department of Obstetrics and Gynecology, Wake Forest University School of Medicine, Medical Center Boulevard, WinstonSalem, NC 27157; e-mail: figueroa@wfubmc.edu.

Funded by National Institutes of Health grant HL68728.

DOI: 10.1203/01.PDR.0000179410.57947.88 association between antenatal glucocorticoid administration and elevations in systolic and diastolic blood pressure (BP) at $14 \mathrm{y}$ of age (5). Studies in animals have also associated administration of glucocorticoids during pregnancy with hypertension in the adult offspring (6-10). However, in these studies, either the dose of glucocorticoids or the developmental stage at which the fetus was exposed does not parallel the clinical use.

Fetal exposure to excess glucocorticoids of maternal origin seems to play a central role in the development of hypertension after fetal undernutrition. Maternal adrenalectomy (11) and inhibition of adrenal function with metyrapone (12) negate the effect of protein restriction on BP, whereas glucocorticoid replacement with corticosterone is sufficient to induce hypertension in the offspring $(11,12)$.

Data from a number of animal models have suggested that one potential mechanism for the development of adult hypertension is altered fetal kidney development (7,13-16). In con- 
trast to rats and mice, in which nephrogenesis is mostly a postnatal event, in humans and sheep, nephrogenesis is completed before birth. Nephrons are observed as early as $14 \mathrm{wk}$ in the human fetus, with peak nephrogenesis occurring at $\sim 24 \mathrm{wk}$ (0.6 of gestation) and ending at $32 \mathrm{wk}$ (0.8 of gestation) (17). Very similar to humans, sheep nephrogenesis is an early fetal event, beginning by $50 \mathrm{~d}$ of gestational age (dGA), peaking at 0.55 of gestation ( $80 \mathrm{dGA}$ ), and ending at 0.8 of gestation (18). Considering the possible effects of glucocorticoids on kidney development and the potential for alterations in renal development to influence BP in adult life, we sought to evaluate the effects of antenatal exposure to glucocorticoids at a gestational age and dose regimen equivalent to that currently used in clinical practice. Specifically, we tested the hypothesis that antenatal administration of glucocorticoids using clinically relevant doses of betamethasone would affect kidney development, renal function, and arterial BP.

\section{METHODS}

Sheep were randomly selected to receive either two doses of $0.17 \mathrm{mg} / \mathrm{kg}$ of a 1:1 mixture of betamethasone acetate and betamethasone phosphate [Celestone Soluspan (Schering, Kenilworth, NJ) $(n=19)]$ or vehicle $(n=23)$. Intramuscular injections were given $24 \mathrm{~h}$ apart at 80 and $81 \mathrm{dGA}$ (term gestation is $145 \mathrm{~d}$ ). Although no sheep received $>12 \mathrm{mg}$ per dose, the premise was that the 12-mg dose represented the amount given to a pregnant woman who weighs $70 \mathrm{~kg}$, which we adjusted to sheep body weight. The animals were studied either as fetuses or as young adults. Pregnant sheep were maintained with free access to food and water in open pasture. For the fetal studies, sheep were brought to the laboratory at $130 \mathrm{dGA}$ for cesarean section delivery of the fetus at $135 \mathrm{dGA}$. For the adult studies, lambs were weaned at $3 \mathrm{mo}$ of age after spontaneous delivery and brought into the laboratory at 6 mo of age. All procedures were approved by the Institutional Animal Cave and Use Committees.

Fetal studies. Pregnant sheep were premedicated with ketamine, ketoprofen, and atropine, and the cesarean section was performed using aseptic conditions under halothane general anesthesia. Fetuses were killed with $4 \mathrm{~mL}$ of Euthasol, dried, and weighed before harvesting of the kidneys. Kidneys were weighed, and the lower half of the right kidney was used to count the number of glomeruli. Nephron counting was performed using the acid maceration method (7). Briefly, the lower half of the right kidney was weighed and minced, and two 0.8 -g aliquots were digested at room temperature in $10 \mathrm{~mL}$ of $8 \mathrm{~N}$ hydrochloric acid for $2 \mathrm{~h}$ on a rocking platform. From each aliquot, fifteen $10-\mu \mathrm{L}$ samples were placed on a graded microscope slide, and glomeruli were counted under phase contrast.

Adult studies. At 6 mo of age, animals were brought into the laboratory for placement of nonocclusive femoral artery and vein catheters. Sheep were housed in a study cart after the surgical procedure. Five days after surgery, the arterial catheter and an open-tip catheter filled with saline were connected to pressure transducers (World Precision Instruments, Sarasota, FL). Pressures were recorded continuously for a minimum of $2 \mathrm{~d}$ using Windaq Pro + data acquisition software (DATAQ Instruments, Inc., Akron, OH). The output of the amplifiers was sampled at $50 \mathrm{~Hz}$, digitized, and stored on the hard disk of a desktop computer. Pressure recorded from the open-tip catheter was used as a reference to subtract pressure changes related to changes in the animal's position. One-minute averages of heart rate and mean, systolic, and diastolic pressures were calculated using custom-designed software (Cruncher; Instrument Concepts Inc., Debert, NS, Canada). The variable used for statistical purposes was the computed mean of 2400 1-min pressure averages over $2 \mathrm{~d}$. Renal function was evaluated by measuring GFR, and effective renal plasma flow was evaluated using inulin and para aminohippuric acid (PAH; Sigma Chemical Co., St. Louis, MO). A bolus of $850 \mathrm{mg}$ of inulin and $225 \mathrm{mg}$ of $\mathrm{PAH}$ was followed by a $10-$ and $11-\mathrm{mg} / \mathrm{min}$ continuous infusion for $3 \mathrm{~h}$, respectively. Samples of arterial blood were obtained after $80 \mathrm{~min}$ of equilibrium time; clearances were calculated using the average of four samples taken 15 min apart. Plasma and urinary electrolytes were measured in samples that were obtained at the time of the clearance study (Medica EasyLyte, Bedford, MA). In addition, circulating levels of angiotensin I, angiotensin II, and plasma and urinary creatinine and urinary protein excretions were measured. These analyses were performed by the Hypertension Core Laboratory at Wake Forest University Health Science Center.
Statistical analysis. Data were expressed as mean \pm SEM and were analyzed by two-sample $t$ test. Differences were considered significant at $p<$ 0.05 .

\section{RESULTS}

Betamethasone administration at 80 and $81 \mathrm{dGA}$ did not induce premature labor. Neonatal losses $(<10 \%)$ were comparable in both groups and were associated with maternal care or poor nursing. As shown in Table 1, there were no significant differences in the number of singleton and twin pregnancies between treated and control animals in either the fetal or the adult groups. Our breeder does not provide information on fetal sex; thus, we had no previous knowledge on fetal sex at the time of randomization for treatment injection. A balanced sex distribution in the treated and control groups was present in the group of animals that were selected for the fetal studies (Table 1). However, this was not the case in the adult study group, in which there were more females born in the betamethasone group than in the control group (Table 1).

Fetal studies. A single course of betamethasone administered at $80 \mathrm{dGA}$ (two $0.17-\mathrm{mg} / \mathrm{kg}$ doses $24 \mathrm{~h}$ apart) was not associated with alterations in fetal body or kidney weights at 135 dGA (Fig. 1). In contrast, a statistically significant decrease in the number of glomeruli was observed. As shown in Fig. 2, the number of glomeruli was significantly reduced when expressed as total number per kidney or normalized for kidney weight ( $p<0.05$ by two-sample $t$ test).

Adult studies. Glucocorticoid administration at $80 \mathrm{dGA}$ did not change gestational length. The mean GA at birth was 144.6 \pm 0.85 versus $143.7 \pm 1.73 \mathrm{~d}$ in vehicle- and betamethasonetreated animals, respectively. Similarly, neither birth weight nor body weight was statistically different at 6 mo (Table 2).

The overall mean, over $2 \mathrm{~d}$, for arterial BP is shown in Fig. 3. A significant elevation in arterial BP was observed in animals that were exposed prenatally to betamethasone at 80 dGA. The elevation in BP was $\sim 8 \mathrm{~mm} \mathrm{Hg}$ for the diastolic, systolic, and mean pressures. In contrast, no significant differences were observed in heart rate over the same study period: $108.8 \pm 5.73$ versus $106.9 \pm 3.47$ beats per minute in control and treated animals, respectively.

Renal function studies performed 1 or $2 \mathrm{~d}$ after the recording of arterial BP yielded no significant differences between groups. As shown in Table 3, GFR measured as inulin clear-

Table 1. Characteristics regarding multiple pregnancy and sex distribution of animals in the Fetal and Adult study groups

\begin{tabular}{lccccc}
\hline & \multicolumn{2}{c}{ Fetal studies } & & \multicolumn{2}{c}{ Adult studies } \\
\cline { 2 - 3 } \cline { 5 - 6 } \cline { 5 - 6 } & Vehicle & Betamethasone & & Vehicle & Betamethasone \\
\hline Dams & 15 & 9 & & 8 & 10 \\
$\quad$ Twins & 6 & 5 & & 2 & 4 \\
$\quad$ Singletons & 9 & 4 & & 7 & 7 \\
Number of fetuses & 21 & 14 & & \\
$\quad$ Female fetuses & 10 & 7 & & \\
$\quad$ Male fetuses & 11 & 7 & & 11 & 15 \\
Number of lambs & & & & 3 & 12 \\
Female lambs & & & & 8 & 3 \\
Male lambs & & & &
\end{tabular}

In both groups study animals were exposed to either vehicle or betamethasone at 80 and 81 days gestational age. 


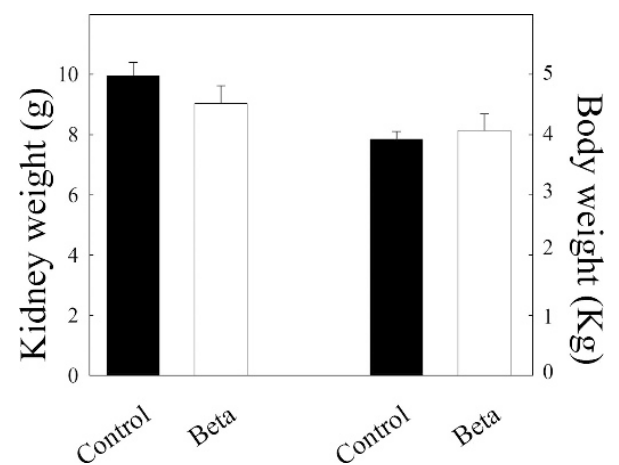

Figure 1. Fetal right kidney weight and fetal body weight at 135 dGA. Fetuses were exposed to either vehicle (Control; $n=21$ ) or betamethasone (Beta; $n=14$ ) via maternal injection of $0.17 \mathrm{mg} / \mathrm{kg}$ at 80 and $81 \mathrm{dGA}$. No significant differences were observed.

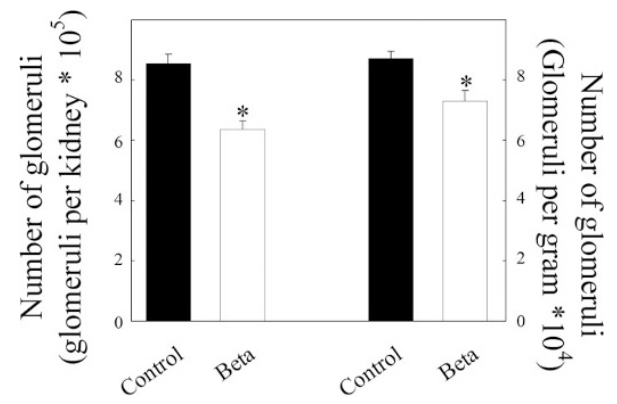

Figure 2. Glomeruli number per kidney and per gram of kidney at $135 \mathrm{dGA}$. Fetuses were exposed to either vehicle (Control; $n=21$ ) or betamethasone (Beta; $n=14$ ) via maternal injection of $0.17 \mathrm{mg} / \mathrm{kg}$ at 80 and $81 \mathrm{dGA}$. A significant decrease in nephron number was observed $\left({ }^{*} p<0.01\right.$ by $t$ test).

Table 2. Characteristics of young adult sheep used for blood pressure recording

\begin{tabular}{lccccc}
\hline & \multicolumn{2}{c}{ Vehicle } & & \multicolumn{2}{c}{ Betamethasone } \\
\cline { 2 - 3 } \cline { 6 - 6 } & Mean & SEM & & Mean & SEM \\
\hline Gestational age (days) & 144.9 & 1.54 & & 144.8 & 1.70 \\
Birth weight (k) & 5.2 & 0.19 & & 4.5 & 0.24 \\
Weight at 6 months & 40.2 & 1.66 & & 40.1 & 1.70 \\
Sample size & 11 & & & 15 & \\
\hline
\end{tabular}

Sheep were exposed to either vehicle or betamethasone at 80 and 81 days of gestational age.

* No significant differences observed in any of the variables.

ance was within the range reported for this species in both groups. Both the absolute GFR and GFR normalized for body surface were not statistically different. Similarly, PAH clearance absolute or normalized for body surface was not statistically different. Also, no differences were observed in the calculated effective renal blood flow. There were no significant differences in plasma concentrations of angiotensin I, angiotensin II, creatinine, and electrolytes (Table 3). Similarly, urinary electrolytes and protein excretion were not statistically different when the two groups were compared (Table 4).

\section{DISCUSSION}

The major finding of this study is that a single course of antenatal steroids alters renal development and is associated with elevations in arterial $\mathrm{BP}$ in the young adult offspring. The importance of the finding lies in the fact that the paradigm

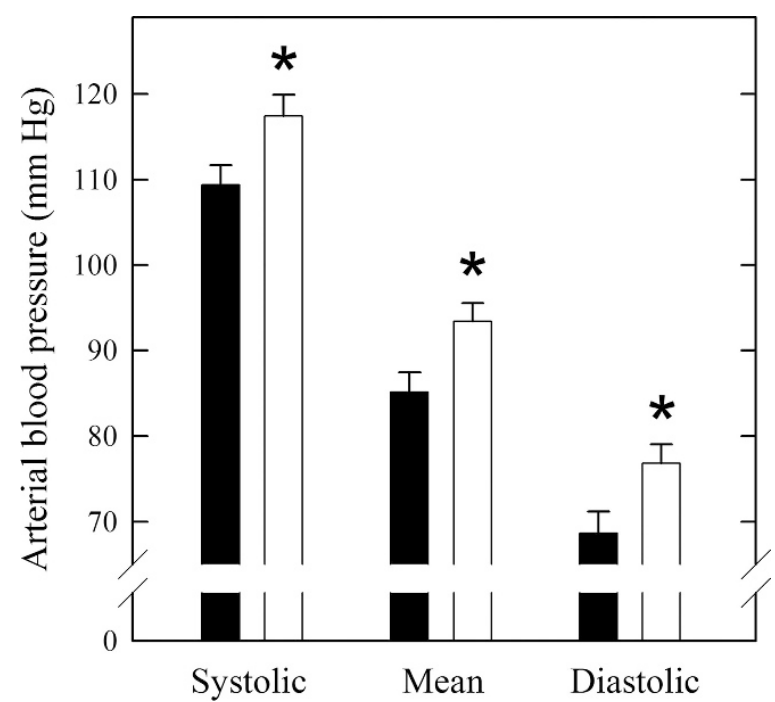

Figure 3. Arterial BP in 6-mo-old sheep that were exposed to either vehicle (Control; $n=11 ; \square$ ) or betamethasone (Beta; $n=15 ; \square$ ) via maternal injection of $0.17 \mathrm{mg} / \mathrm{kg}$ at 80 and $81 \mathrm{dGA}$. Pressures represent the overall average of 2400 1-min pressure averages over $2 \mathrm{~d}$. A significant increase in BP was observed in the betamethasone group $\left({ }^{*} p<0.05\right.$ by two-sample $t$ test).

models the clinical situation in two ways. First, the dose of betamethasone administered to the ewe $(0.17 \mathrm{mg} / \mathrm{kg}$ body weight) is equivalent to the $12-\mathrm{mg}$ dose recommended by the National Institutes of Health consensus panel (2). Second, the selection of the GA was based on the fact that at $80 \mathrm{~d}$, the developmental stage of the fetal sheep kidney closely resembles that of the human fetus at 24 wk gestation, which is an age when glucocorticoids are used clinically. Our study has the advantage of removing the confounding effect of prematurity and clinical management of the premature in the analysis. Also, our BP data represent a continuous recording of BP in a relatively stress-free environment, which suggests that the difference that we observed represents an effect on basal BP rather than a difference in stress effects on BP.

Total number of nephrons is the result of a multiplying effect of ureteric bud branching; thus, a small impairment early in this process can have profound effects on nephron number. It has been estimated that a $2 \%$ decrease in the efficiency of ureteric bud branching will yield kidneys with nephron numbers reduced by $50 \%$ after 20 generations of branching (19). Our finding of a $25 \%$ decrease in the number of glomeruli in the kidney of fetuses that were examined at $135 \mathrm{dGA}$ is in keeping with the decrease reported in other species after protein restriction or glucocorticoid administration $(7,14,16,20)$. In sheep, nephrogenesis is thought to end by 120 $\mathrm{dGA}$; thus, we believe that the reduction in glomeruli number found in the fetus will persist in the adult. Betamethasone rapidly crosses the sheep placenta, and after a maternal intramuscular injection, fetal plasma levels remain elevated for several hours. The calculated half-life is $8 \mathrm{~h}(21)$. The available data for human fetuses closely resembles the sheep pharmacokinetic data in terms of both plasma levels achieved and half-life (22). Although fetuses were exposed for a relatively short time to high concentrations of glucocorticoids, we propose that this exposure is sufficient to alter the expression of 
Table 3. Indices of renal function (Inulin and PAH clearance) and plasma concentrations of angiotensin peptides, electrolytes and creatinine young adult sheep exposed to either vehicle or betamethasone at 80 and 81 days gestational age*

\begin{tabular}{|c|c|c|c|c|}
\hline & \multicolumn{2}{|c|}{ Vehicle } & \multicolumn{2}{|c|}{ Betamethasone } \\
\hline & Mean & SEM & Mean & SEM \\
\hline Angiotensin I & 33.6 & 6.00 & 41.2 & 12.2 \\
\hline Sodium $(\mathrm{mEq} / \mathrm{L})$ & 148.3 & 0.54 & 148.7 & 0.43 \\
\hline Potassium (mEq/L) & 4.3 & 0.12 & 4.3 & 0.05 \\
\hline Chloride (mEq/L) & 106.1 & 0.71 & 106.4 & 0.67 \\
\hline PAH§ clearance $(\mathrm{ml} / \mathrm{min})$ & 805.9 & 56.31 & 764.3 & 39.07 \\
\hline Sample size & 10 & & 8 & \\
\hline
\end{tabular}

* No significant differences observed in any of the variables.

$\S$ PAH, Para amino hippuric acid.

Table 4. Urine electrolyte and protein concentration in young adult sheep exposed to either vehicle or betamethasone at 80 and 81 days gestational age*

\begin{tabular}{|c|c|c|c|c|}
\hline & \multicolumn{2}{|c|}{ Vehicle } & \multicolumn{2}{|c|}{ Betamethasone } \\
\hline Sodium (mEq/L) & 138.3 & 6.7 & 166.0 & 12.5 \\
\hline Chloride (mEq/L) & 312.2 & 24.5 & 345.4 & 39.8 \\
\hline Creatinine $(\mathrm{mg} / \mathrm{dL})$ & 0.74 & 0.03 & 0.73 & 0.03 \\
\hline Protein ( $\mathrm{mg} / \mathrm{mg}$ Creatinine) & 0.93 & 0.07 & 0.98 & 0.08 \\
\hline
\end{tabular}

* No significant differences observed in any of the variables.

regulatory molecules or growth factors that control nephrogenesis. Among these factors, the protooncogene c-ret or its ligand Glial cell line-derived neurotrophic factor and components of the renin-angiotensin system (RAS) are the most likely candidates. Addition of c-ret antisense oligonucleotides to mouse metanephric organ cultures reduces ureteric duct branching (23), and the loss of one Glial cell line-derived neurotrophic factor allele results in reduced nephron endowment in the adult kidney (24). Most important, dexamethasone reduces c-ret mRNA and protein expression in a thyroid tumor cell line in a dose- and time-dependent manner (25).

Several reports indicate that the RAS is critically important for renal development and growth. Mice with targeted mutations of the angiotensinogen-converting enzyme or angiotensin receptor type $1_{\mathrm{A}}\left(\mathrm{AT} 1_{\mathrm{A}}\right)$ and $\mathrm{AT} 1_{\mathrm{B}}$ receptor genes have marked kidney morphologic alterations (26-28). Similarly, AT2 receptor gene deletion is associated with an increased incidence of congenital anomalies of the kidney and urinary tract (29). Renin is found in fetal sheep kidney as early as 41 dGA (30), and by $90 \mathrm{dGA}$, kidney renin content and mRNA are higher than maternal values $(31,32)$. In fetal sheep, AT1 receptors are present in the kidney by $60 \mathrm{dGA}$, and after $80 \mathrm{dGA}$, there is an increase in AT1 receptor mRNA expression in cortex, where it is localized in the juxtamedullary area extending to the outer medulla (18). AT2 receptors are also found in fetal kidney as early as $60 \mathrm{~d}$, and the temporal profile for the expression of AT2 receptor mRNA is reminiscent of changes in nephrogenesis, particularly the abrupt decline at $120 \mathrm{dGA}$ in sheep, a time at which nephron differentiation is ending. Administration of synthetic glucocorticoids in doses comparable to those used for inducing lung maturation decreases plasma renin activity, angiotensin II, and aldosterone concentrations in late-gestation fetal sheep $(33,34)$.

The relationship between the reduction in nephron number and the development of hypertension is still unresolved. The nephron endowment hypothesis proposed by Brenner et al. (35) predicts that a reduction in nephron number decreases sodium filtration, leading to an expansion of extracellular fluid volume. Several reports have documented a reduction in nephron number in protein restriction and prenatal steroid models of fetal programming $(15,16)$. However, the decrease in the number of glomeruli ranges between 25 and 30\%, with even smaller changes in total renal GFR. This is a relatively small decrease in nephron number to explain the elevations in $\mathrm{BP}$, particularly in younger individuals in whom single nephron hyperfiltration has not translated into nephrosclerosis. The reduction in nephron number that we have observed was not associated with a decrease in kidney weight, which suggests that there was compensatory growth in tubular structures. It therefore is possible that in addition to the reduction in glomerular mass, the compensatory growth of tubular structures participates in the development of hypertension. Recently, evidence for alterations in tubular reabsorption was obtained in the rat protein restriction model of fetal programming. Of the four key apical sodium transporters, only bumetanide-sensitive $\mathrm{Na}-\mathrm{K}-2 \mathrm{Cl}$ co-transporter and thiazide-sensitive $\mathrm{Na}-\mathrm{Cl}$ co-transporter, the transporters of the thick ascending part of the loop of Henle and distal convoluted tubule, were shown to be up-regulated at the mRNA and protein levels at 4 and 8 wk of age (36). In addition, the kidneys in offspring of protein-restricted rats had permanent increases in mRNA expression for the $\alpha 1$ and $\beta 1$ subunits of the Na,K ATPase (37). 
Plasma concentrations of angiotensin I and II were not altered by antenatal steroid exposure. This finding is in keeping with the data of Wintour et al. (15) and suggests that up-regulation of the RAS does not play a significant causative role in the elevation of BP. However, the involvement of the intrarenal RAS cannot be ruled out.

Our data show that by 6 mo of age, the offspring of sheep that were treated with betamethasone have an elevation in arterial $\mathrm{BP}$ of $\sim 8 \mathrm{~mm} \mathrm{Hg}$. Elevations in arterial BP, although common in the different paradigms of fetal programming, e.g. protein restriction or glucocorticoid administration during pregnancy, are not always present. For example, dexamethasone $(12 \mathrm{mg} / \mathrm{d})$ or cortisol $(120 \mathrm{mg} / \mathrm{d})$ for $2 \mathrm{~d}$ at day 26 of gestation causes increased BP in the offspring, whereas administration at day 60 does not $(8-10)$. Also, Moss et al. (21) showed that a single dose or multiple weekly doses of betamethasone $\left(0.5 \mathrm{mg} \cdot \mathrm{kg}^{-1} \cdot \mathrm{dose}^{-1}\right)$ starting at $105 \mathrm{dGA}$ significantly reduced birth weight but did not elevate arterial BP in the adult offspring. In these studies, both the control and betamethasone groups were treated with progesterone to prevent premature labor. It is possible that previous exposure to progesterone protects the kidney from the deleterious effects of glucocorticoids. Also, it is important to consider the vulnerability of the fetal kidney to glucocorticoids at different developmental stages. Different sensitivity to glucocorticoids may result from the absence of factors that mediate the response, e.g. 60-d-old sheep or because most branching of the ureteric bud is completed by $105 \mathrm{dGA}$ in the sheep fetus. The human fetus may also show differential sensitivity to the long-term effects of glucocorticoids. In the report of Doyle et al. (5), a small but significant elevation in BP was evident at $14 \mathrm{y}$ of age in a cohort who received betamethasone at an average of $28 \mathrm{wk}$ gestation. In contrast, no elevations in BP were found when antenatal glucocorticoids were administered at an average of $32 \mathrm{wk}$ gestation (38).

The present study, like many others, cannot rule out the involvement of other systems in the development of hypertension. Fetal programming, as currently understood, represents the fetal response to an adverse intrauterine environment. Which organ system(s) is(are) affected will depend on the intensity of the stimulus and the differential vulnerability of different organs at any given GA. This study was designed to explore the possibility of glucocorticoids' affecting renal development at a GA when kidney branching and morphogenesis are at their highest rate, which in humans is 24 wk gestation. Our data have documented the vulnerability of the fetal kidney to clinically relevant doses of betamethasone at a gestational stage when human fetuses are routinely exposed to glucocorticoids if the mother is threatened with premature delivery. Thus, our findings strongly suggest that despite the absence of acute side effects, antenatal glucocorticoid administration under the National Institutes of Health consensus guidelines may alter human fetal renal development. Further studies are needed to establish a direct relationship between alterations in renal development and the development of hypertension.

\section{REFERENCES}

1. Liggins GC, Howie RN 1972 A controlled trial of antepartum glucocorticoid treatment for prevention of the respiratory distress syndrome in premature infants. Pediatrics 50:515-525

2. NIH Consensus Development Panel on the Effect of Corticosteroids for Fetal Maturation on Perinatal Outcomes. 1995 Effect of corticosteroids for fetal maturation on perinatal outcomes. JAMA 273:413-418

3. Leviton LC, Goldenberg RL, Baker CS, Schwartz RM, Freda MC, Fish LJ, Cliver SP, Rouse DJ, Chazotte C, Merkatz IR, Raczynski JM 1999 Methods to encourage the use of antenatal corticosteroid therapy for fetal maturation: a randomized controlled trial. JAMA 281:46-52

4. Jobe AH 2000 Glucocorticoids in perinatal medicine: misguided rockets? J Pediatr 137:1-3

5. Doyle LW, Ford GW, Davis NM, Callanan C 2000 Antenatal corticosteroid therapy and blood pressure at 14 years of age in preterm children. Clin Sci 98:137-142

6. Levitt NS, Lindsay RS, Holmes MC, Seckl JR 1996 Dexamethasone in the last week of pregnancy attenuates hippocampal glucocorticoid receptor gene expression and elevates blood pressure in the adult offspring in the rat. Neuroendocrinology 64:412418

7. Celsi G, Kistner A, Aizman R, Eklof AC, Ceccatelli S, de Santiago, Jacobson SH 1998 Prenatal dexamethasone causes oligonephronia, sodium retention, and higher blood pressure in the offspring. Pediatr Res 44:317-322

8. Dodic M, Tangalakis K, Moritz K, McFarlane A, Wintour EM 1998 Fluid abnormalities occur in the chronically cannulated mid-gestation but not late gestation ovine fetus. Pediatr Res 44:894-899

9. Dodic M, Abouantoun T, O’Connor A, Wintour EM, Moritz KM 2002 Programming effects of short prenatal exposure to dexamethasone in sheep. Hypertension 40:729734

10. Dodic M, Hantzis V, Duncan J, Rees S, Koukoulas I, Johnson K, Wintour EM, Moritz K 2002 Programming effects of short prenatal exposure to cortisol. FASEB J 16:1017-1026

11. Gardner DS, Jackson AA, Langley-Evans SC 1997 Maintenance of maternal dietinduced hypertension in the rat is dependent on glucocorticoids. Hypertension 30:1525-1530

12. Langley-Evans SC 1997 Hypertension induced by foetal exposure to a maternal low-protein diet, in the rat, is prevented by pharmacological blockade of maternal glucocorticoid synthesis. J Hypertens 15:537-544

13. Nwagwu MO, Cook A, Langley-Evans SC 2000 Evidence of progressive deterioration of renal function in rats exposed to a maternal low-protein diet in utero. Br J Nutr 83:79-85

14. Langley-Evans SC, Welham SJ, Jackson AA 1999 Fetal exposure to a maternal low protein diet impairs nephrogenesis and promotes hypertension in the rat. Life Sci 64:965-974

15. Wintour EM, Johnson K, Koukoulas I, Moritz K, Tersteeg M, Dodic M 2003 Programming the cardiovascular system, kidney and the brain-a review. Placenta 24:S65-S71

16. Wintour EM, Moritz KM, Johnson K, Ricardo S, Samuel CS, Dodic M 2003 Reduced nephron number in adult sheep, hypertensive as a result of prenatal glucocorticoid treatment. J Physiol 549:929-935

17. Crocker JF, Brown DM, Vernier RL 1971 Developmental defects of the kidney. A review of renal development and experimental studies of maldevelopment. Pediatr Clin North Am 18:355-376

18. Gimonet V, Bussieres L, Medjebeur AA, Gasser B, Lelongt B, Laborde K 1998 Nephrogenesis and angiotensin II receptor subtypes gene expression in the fetal lamb. Am J Physiol 274:F1062-F1069

19. Sakurai H, Nigam SK 1998 In vitro branching tubulogenesis: implications for developmental and cystic disorders, nephron number, renal repair, and nephron engineering. Kidney Int 54:14-26

20. Vehaskari VM, Aviles DH, Manning J 2001 Prenatal programming of adult hypertension in the rat. Kidney Int 2001 59:238-245

21. Moss TJ, Doherty DA, Nitsos I, Harding R, Newnham JP 2003 Pharmacokinetics of betamethasone after maternal or fetal intramuscular administration. Am J Obstet Gynecol 189:1751-1757

22. Ballard PL, Granberg P, Ballard RA 1975 Glucocorticoid levels in maternal and cord serum after prenatal betamethasone therapy to prevent respiratory distress syndrome. J Clin Invest 56:1548-1554

23. Liu ZZ, Wada J, Kumar A, Carone FA, Takahashi M, Kanwar YS 1996 Comparative role of phosphotyrosine kinase domains of c-ros and c-ret protooncogenes in metanephric development with respect to growth factors and matrix morphogens. Dev Biol 178:133-148

24. Cullen-McEwen LA, Drago J, Bertram JF 2001 Nephron endowment in glial cell line-derived neurotrophic factor (GDNF) heterozygous mice. Kidney Int 60:31-36

25. Capes-Davis A, Andrew SD, Hyland VJ, Twigg S, Learoyd DL, Dwight T, Marsh DJ, Robinson BG 1999 Glucocorticoids differentially inhibit expression of the RET proto-oncogene. Gene Expr 8:311-326

26. Hilgers KF, Reddi V, Krege JH, Smithies O, Gomez RA 1997 Aberrant renal vascular morphology and renin expression in mutant mice lacking angiotensin-converting enzyme. Hypertension 29:216-221

27. Nagata M, Tanimoto K, Fukamizu A, Kon Y, Sugiyama F, Yagami K, Murakami K, Watanabe T 1996 Nephrogenesis and renovascular development in angiotensinogendeficient mice. Lab Invest 75:745-753

28. Oliverio MI, Kim HS, Ito M, Le T, Audoly L, Best CF, Hiller S, Kluckman K, Maeda N, Smithies O, Coffman TM 1998 Reduced growth, abnormal kidney structure, and type 2 (AT2) angiotensin receptor-mediated blood pressure regulation in mice lacking 
both AT1A and AT1B receptors for angiotensin II. Proc Natl Acad Sci USA 95:15496-15501

29. Nishimura H, Yerkes E, Hohenfellner K, Miyazaki Y, Ma J, Hunley TE, Yoshida H, Ichiki T, Threadgill D, Phillips JA, Hogan BM, Fogo A, Brock JW, Inagami T, Ichikawa I 1999 Role of the angiotensin type 2 receptor gene in congenital anomalies of the kidney and urinary tract, CAKUT, of mice and men. Mol Cell 3:1-10

30. Moritz KM, Wintour EM 1999 Functional development of the meso- and metanephros. Pediatr Nephrol 13:171-178

31. Zhang DY, Lumbers ER, Simonetta G 1996 Changes in renal renin gene expression in fetal sheep. Clin Exp Pharmacol Physiol 23:682-684

32. Carbone GM, Sheikh AU, Zehnder T, Rose JC 1995 Effect of chronic infusion of cortisol on renin gene expression and renin response to hemorrhage in fetal lambs. Pediatr Res 37:316-320

33. Smith LM, Ervin MG, Wada N, Ikegami M, Polk DH, Jobe AH 2000 Antenatal glucocorticoids alter postnatal preterm lamb renal and cardiovascular responses to intravascular volume expansion. Pediatr Res 47:622-627
34. Berry LM, Polk DH, Ikegami M, Jobe AH, Padbury JF, Ervin MG 1997 Preterm newborn lamb renal and cardiovascular responses after fetal or maternal antenatal betamethasone. Am J Physiol 272:R1972-R1979

35. Brenner BM, Mackenzie HS 1997 Nephron mass as a risk factor for progression of renal disease. Kidney Int Suppl 63:S124-S127

36. Manning J, Beutler K, Knepper MA, Vehaskari VM 2002 Upregulation of renal BSC1 and TSC in prenatally programmed hypertension. Am J Physiol 283:F202F206

37. Bertram C, Trowern AR, Copin N, Jackson AA, Whorwood CB 2001 The maternal diet during pregnancy programs altered expression of the glucocorticoid receptor and type $211 \beta$-hydroxysteroid dehydrogenase: potential molecular mechanisms underlying the programming of hypertension in utero. Endocrinology 142:28412853

38. Dalziel SR, Liang A, Parag V, Rodgers A, Harding JE 2004 Blood pressure at 6 years of age after prenatal exposure to betamethasone: follow-up results of a randomized, controlled trial. Pediatrics 114:e373-e377 